\title{
Crises

\section{Host - e a dificuldade de se fazer Cinema}

Pedro Victor Viana Coutinho de Oliveira Farias ${ }^{1}$

Resumo: Esta resenha crítica faz uma análise técnica e narrativa do filme de Terror Host (2020). Para além desses pontos contidos dentro da própria obra, será analisada uma questão externa, que é a dificuldade de se fazer cinema em um período complicado e caótico como a pandemia do coronavírus. Junto a esse aspecto, serão também feitas relações com alguns outros filmes, em especial Apocalypse Now (1979), mostrando que mesmo em outra época e com outros aspectos, as dificuldades na arte de se fazer cinema se mantém e em muitas ocasiões podem até ajudar na qualidade da obra e na sua importância dentro da comunidade cinéfila.

Palavras-chave: Host. Cinema. Pandemia. Apocalypse Now.

No final de 2019, surgem na China os primeiros casos de uma nova doença causada pelo Coronavírus SARS-CoV-2, chamada de Covid-19. A Covid-19, de acordo com o ministério da saúde, é uma infecção respiratória de elevada transmissibilidade que se propaga por meio do contato direto de pessoa para pessoa através de gotículas de saliva, toque do aperto de mãos, contato com superfícies contaminadas, etc.

Como resultado da rápida transmissão do vírus, após alguns meses este se espalhou por praticamente todos os lugares do mundo e modificou completamente a estrutura e funcionamento dos países. Sistemas de saúde entraram em crise, o livre andar foi restringido na tentativa de diminuir a transmissão do vírus, várias pessoas tiveram os seus empregos perdidos ou tiveram que trabalhar em casa e infelizmente milhões de pessoas morreram em decorrência da doença. Tudo isso causou uma grande crise sanitária, econômica e social.

As redes de trabalho que envolvem o Cinema foram uma das profissões mais afetadas com a pandemia. Salas de exibição no mundo todo foram fechadas, fazendo com que muitas redes e salas de cinema fechassem, o que causou uma demissão em

1 Graduando do Curso de Comunicação Social pela Universidade Federal de Pernambuco do Campus Acadêmico do Agreste. E-mail: Pedro68viana@gmail.com 


\section{Crisevista

massa que atingiu desde o gerente até o vendedor de pipocas. De acordo com uma matéria publicada pela Forbes, os serviços de aluguel online, como do Youtube e da Apple Store e de streaming como Netflix, Disney Plus, Amazon Prime e Globo Play cresceram ainda mais e muitas produções que estavam sendo gravadas precisaram ser interrompidas. Com isso, toda a estrutura das artes visuais, em especial o cinema, foi modificada, causando uma das maiores crises da história da sétima arte. Assim, surgiram as perguntas dos consumidores de audiovisual: qual será o primeiro filme a ser realizado com as restrições provocadas pela pandemia? E ainda mais, qual será o primeiro a abordar essa temática?

A resposta está no filme de terror Host (2020), do jovem diretor Rob Savage. Na obra, um grupo de 5 amigas e 1 amigo se juntam em uma reunião online via Zoom, serviço de videoconferência online, com uma médium. A partir disso, uma das mulheres acaba zombando dos espíritos, fazendo com que essas forças sobrenaturais se descontrolem e as atormentem de uma maneira violenta e assustadora.

O longa se passa na Inglaterra nos primeiros meses da pandemia da Covid-19, o que é explicado no início do longa em um diálogo entre duas personagens. Além disso, o filme se passa no início desse caos mundial, época em que a comunidade científica ainda não tinha respostas e nem muito menos uma possível vacina, sendo assim, o medo invisível e intangível do desconhecido se multiplicava entre as pessoas.

A solidão também é um ponto chave para entender o filme. As participantes estão no tédio completo, muitas não têm o que fazer e nem com quem conversar, isso é exemplificado por uma das personagens que simplesmente se grava e se coloca como plano de fundo na chamada, mostrando assim que é uma pessoa com bastante tempo livre. Sendo assim, elas decidem fazer essa chamada online, pois podem se encontrar, conversar (mesmo sendo virtualmente) e terão algo de novo para fazer.

A construção das personagens é feita de maneira bem detalhada e progressiva. Existe verdade dentro daquele ciclo de amizades e isso acontece pois contém ótimas atuações das atrizes, fazendo com que essas interações não sejam forçadas ou caricatas. Isso se deve aos diálogos entre elas que são muito bem escritos e exploram bem essa relação de saudade, já que elas não se veem mais presencialmente. 


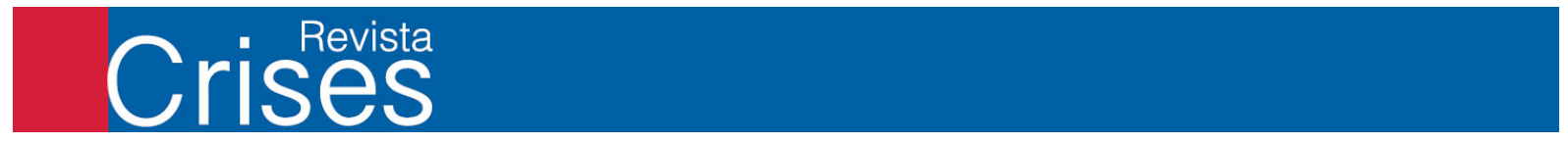

Já a estrutura do arco dramático passa de bons para péssimos momentos. 0 começo do filme, ou o primeiro ato, é marcado por uma apresentação detalhada dos personagens e da trama, trazendo pequenos aspectos de suspense que podem deixar muitos telespectadores tensos. Entretanto, essa construção detalhada acaba por dar lugar a uma ação desenfreada e até mesmo mal feita no terceiro (e último) ato, tendo algumas cenas mal gravadas, com efeitos especiais de baixa qualidade e uma grande quantidade de clichês.

A decepção com a obra depois disso é inevitável, pois toda aquela criação peculiar de mundo, com plano de fundo na realidade, acaba dando lugar a mais uma história de terror qualquer.

Entretanto, a forma em que o filme é gravado é um dos detalhes técnicos que mais chamam atenção. O longa emula uma chamada pelo Zoom, o que significa que o que vemos em tela é justamente a imagem de computador, como se o próprio telespectador estivesse naquela chamada junto das outras pessoas.

Esse foi um artifício que, embora não tenha sido original, (filmes como Buscando... (2018) já haviam utilizado) conseguiu se encaixar perfeitamente na ideia proposta pelo diretor. A emulação da situação pandêmica é feita com maestria por isso: a partir da quarentena, as videochamadas se tornaram muito mais comuns e para muitas pessoas foi a única forma de comunicação existente. Por isso mesmo que o seu começo é tão assustador, pois é uma história de terror sobrenatural, em um ambiente "real" e conhecido pelas pessoas.

Contudo, o que mais chama a atenção em Host é sua produção, afinal, ela se deu em plena pandemia do Coronavírus. O diretor Rob Savage, assim como milhões de pessoas, estava inquieto e improdutivo em casa e decidiu gravar um filme para apaziguar essa vontade interior. Mas não seria qualquer projeto, precisava ser um que se passasse dentro daquele cenário e fosse gravado de uma forma diferente: online.

O filme foi gravado todo nessa ideia de lockdown, dirigido à distância, cada atriz fez sua própria atuação em casa, os ensaios foram feitos via videoconferência e a montagem da obra também foi realizada assim. Segundo o próprio diretor em uma entrevista realizada no canal do Youtube HeyUGuys, ele e a produção se sentiram bastante livres e confiantes em realizar essa experiência cinematográfica, afirmando que "era um dos 


\section{Crisevista

filmes em que nós tínhamos um passe livre, pois se desse errado, tínhamos a desculpa de culpar o ambiente, mas se desse certo, seria ótimo e de qualquer forma seria divertido" (HeyUGuys, 2020).

Embora Savage tenha dito que tinha um "passe livre", eu não consigo parar de pensar em todas as dificuldades e nos desafios que ele e a produção tiveram na construção dessa obra. De acordo com uma entrevista de Savage ao canal do Youtube HeyUGuys, a escrita do roteiro foi feita com muita rapidez, o que pode explicar os problemas no terceiro ato. A produção tinha a intenção de fazer o primeiro filme nessa temática, com isso eles tinham uma espécie de bomba relógio sobre si mesmos. Caso outro projeto fosse lançado uma semana antes, todo o esforço e ambição teriam sido destruídos e muito provavelmente eu não estaria escrevendo agora sobre Host e sim sobre esse outro hipotético longa-metragem.

Isso pode explicar em parte os erros de roteiro cometidos no terceiro ato. Muito provavelmente ele foi escrito em uma velocidade maior e não teve tanto tempo para revisão, sendo assim, aposta em algo mais previsível e pouco inspirado.

Outra dificuldade é a direção. O diretor, em tese, precisa de um contato próximo em todos os aspectos do filme: roteiro (se ele próprio não tiver escrito), elenco, fotografia, produção, som, efeitos e etc. Rob Savage realizou tudo isso online, com um distanciamento técnico e pessoal. Isso pode novamente ser a explicação para alguns problemas do longa, em especial no final do filme, afinal o diretor funciona como uma espécie de "presidente" do filme, é ele que toma as decisões técnicas, narrativas e dirige os atores, por isso ele precisa estar presente, atento e próximo a todas essas questões, mas ainda sim é um trabalho que precisa ser exaltado, pois foi algo bastante diferente, arriscado e que trouxe muitos acertos.

Embora Savage tenha dito que se desse errado tinha uma desculpa, acredito que isso não aconteceria na realidade. Se o filme fosse horrível, depois de ter um grande marketing boca a boca, por ser o primeiro da pandemia, o nome dele poderia já ter um aspecto negativo. Diversos diretores de grande importância tiveram marcas negativas tão grandes que muitos não conseguem se livrar delas.

Vejamos o exemplo de M Night Shyamalan, que depois de um começo impressionante no cinema, tendo dirigido grandes obras como "O Sexto Sentido e Corpo 


\section{Crisevista

Fechado", realizou alguns filmes de qualidade duvidosa, como "O Último Mestre do Ar" e, por isso, mesmo tendo lançado bons filmes depois de muito tempo como "Fragmentado", seu trabalho ainda causa uma certa desconfiança. Sendo assim, para Rob Savage, um jovem diretor sem muita bagagem e experiência, tal erro poderia ter sido um golpe tão pesado em sua carreira que talvez ele nunca teria conseguido reverter.

Dentre todos esses problemas, outro ainda merece destaque: o baixo orçamento para realização do longa é um detalhe técnico bastante perceptível, em especial nas cenas em que o "espírito" aparece. Porém, mesmo com essas dificuldades, o diretor conseguiu reverter bem essa situação em alguns momentos. Um dos recursos utilizados foi a baixa iluminação, tornando o filme escuro para observar muitos defeitos. Outro recurso utilizado foi a mudança de câmera nas vídeo chamados, assim, quando algo acontece, a imagem é trocada para outra personagem, dificultando a possibilidade de se observar defeitos técnicos.

Vendo todos esses problemas de produção, de ambientação e de orçamento, um filme me veio à cabeça: Apocalypse Now (1979). Mas o que uma das obras mais importantes do cinema, considerado o trigésimo melhor filme Norte Americano da História pelo American Film Institute, teria a ver com Host, de 2020? Analisando tecnicamente não existe nenhuma semelhança, mas observando as inquietações dos diretores, consigo traçar alguns paralelos com a obra.

Os bastidores da famosa obra de guerra são um dos mais conhecidos e conturbados da história do cinema, muito por causa do documentário dirigido por Eleanor Coppola, esposa de Francis Ford Coppola, Heart of Darkness, o Apocalypse de um cineasta.

Nesse documentário são mostrados os bastidores caóticos do filme. Dentre algumas coisas absurdas que aconteceram na produção, Coppola teve uma vontade gigantesca de se desafiar a fazer o que seria, segundo ele, o maior filme da história. Isso fez com que ele custeasse grande parte do orçamento do filme com recursos próprios e o fez ter problemas pessoais de grande magnitude, como ataques epiléticos, perca de peso e pensamentos suicidas. Além disso, o roteiro teve diversos problemas, modificações e precisou ser reescrito várias vezes durante as gravações. 


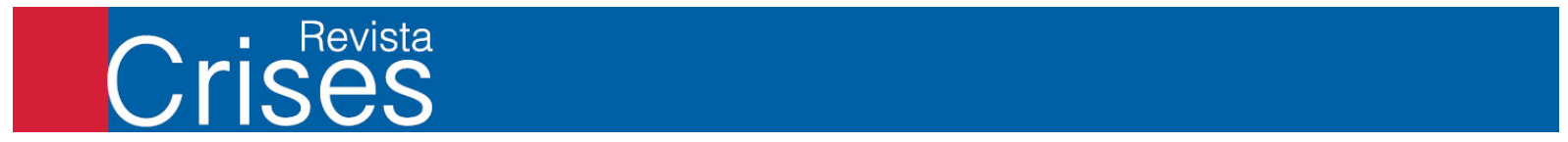

Os bastidores foram marcados também por acidentes: Martin Sheen, o ator principal, sofreu um infarto no meio das gravações e uma chuva alagou toda a produção da obra. Além disso, Marlon Brando causou diversos obstáculos no set de filmagens, pois ele não havia lido o roteiro previamente e não sabia do que a história se tratava, somado a isso, estava muito acima do peso previsto para o seu personagem e se recusava a filmar com o ator Dennis Hopper, que por sinal, estava fazendo uso de cocaína para sua interpretação. O tempo de gravação durou 8 meses, algo simplesmente absurdo para trabalhos cinematográficos dessa relevância que em média duram de 8 a 12 semanas. A montagem do projeto também durou vários anos, sendo algo que ainda hoje atormenta o diretor, que já relançou o filme diversas vezes ao longo dos anos.

Assim, consigo ver algumas semelhanças entre os dois; embora cada um tenha seus problemas peculiares, ambos se desafiaram a fazer algo novo e marcante e ambos tiveram grandes dificuldades em realizar a obra. No caso de Host, isso se deve muito mais ao seu momento temporal no mundo, uma das épocas mais difíceis dos últimos anos e a toda diferença na forma de filmagem online.

Óbvio que não são somente esses filmes ou esses diretores que se desafiaram, dezenas de outras pessoas fizeram isso e talvez aí esteja um dos pontos mais importantes na arte de se fazer cinema: o desafio. Tocar em assuntos desagradáveis, testar algo tecnicamente novo, fazer um filme mesmo sem ter o dinheiro para tal, produzir algo que tenha sentido e valor são algumas das marcas para realização de um grande cinema.

Ingmar Bergman tocava em temas que eram extremamente desagradáveis para ele, David Lynch já realizou grandes projetos com orçamentos baixíssimos, o próprio Coppola em Apocalypse Now, um diretor consagrado, se desafiou para realizar um filme que poderia ter o levado à falência e descrédito total.

Entretanto, entendo que esse desafio não seja a única coisa necessária para um filme ser considerado bom ou atingir o seu objetivo previsto, pois ele precisa de um aspecto fundamental que é a técnica. Mas somente esse ato já coloca essas obras em um lugar de destaque ou, pelo menos, de diferença comparada a grande quantidade de filmes que saem semanalmente e que não tem nada para dizer. 


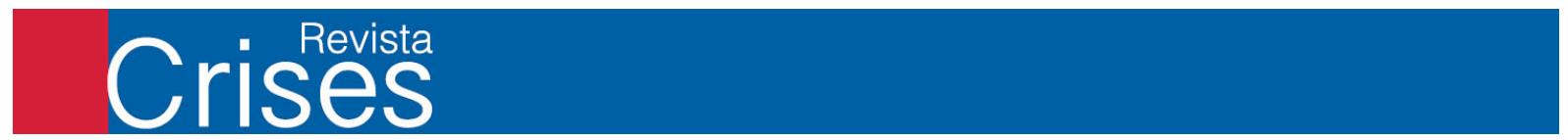

Talvez Host não seja um filme que entre para história devido ao seu roteiro ou detalhes técnicos, mas pelo fato de ter sido produzido durante a pandemia. Acredito que será alvo de muito estudo no futuro e conseguirá ter um grande valor histórico, sendo fruto, principalmente, da vontade do diretor em se desafiar e fazer algo novo.

\section{Referências:}

APOCALYPSE now. Direção de Francis Ford Coppola. Estados Unidos da América: United Arts, 1979. 1 DVD (153min).

BUSCANDO.... Direção de Aneesh Chaganty. Estados Unidos da América: Sony Pictures, 2018. 1 Filme (102min).

CORONAVÍRUS: 577 salas de cinema do Brasil já foram fechadas. OGlobo,16 de março de 2020. Disponível em <https://oglobo.globo.com/cultura/coronavirus-577-salas-de-cinema-do-brasil-ja-foramfechadas-24308759> Acesso em: 13 de abril 2021.

CORPO Fechado. Direção de M Night Shyamalan. Estados Unidos da América: Buena Vista Pictures, 2000. 1 DVD (106min).

FRAGMENTADO. Direção de M Night Shyamalan. Estados Unidos da América: Universal Pictures, 2016. 1Filme (117 min).

HOST. Direção de Rob Savage. Estados Unidos da América: ShadowhouseFilms, 2020. 1 Filme (65min).

HEYUGUYS, Host Director Rob Savage on making the scariest film of 2020. Youtube, 2020. Disponível em: <https://www.youtube.com/watch?v=yFCukJzA7o8\&t=592s>. Acesso em: 10 de Abril de 2021.

HEARTS of Darkness: A Filmmaker's Apocalypse. Direção de Eleanor Coppola, George Hickenlooper e Fax Bahr. Estados Unidos da America: American Zoetrope, 1991. 1VHS (97min).

O SEXTO Sentido. Direção de M Night Shyamalan. Estados Unidos da América: Buena Vista Pictures, 1999. 1 Filme (107min).

O ÚLTIMO Mestre do ar. Direção de M Night Shyamalan. Estados Unidos da América: Paramount Pictures, 2010. 1 DVD (103min).

STREAMING ganha ainda mais relevância com o isolamento social. Forbes, 30 agosto de 2020. Disponível em: <https://forbes.com.br/principal/2020/08/streaming-ganha-aindamais-relevancia-com-o-isolamento-social/). Acesso em 13 de abril de 2021. 